\title{
Id Reaction : An Overlooked Reaction of a Common Problem
}

\author{
Pathak $\mathrm{D}^{1}$
}

${ }^{1}$ Deeptara Pathak, Consultant Dermatologist, Delhi Dermatology Group Kubba Clinic

\begin{abstract}
A 15 year old boy presented with sudden onset of pompholyx like eruption on acral areas involving bilateral hands and feet for 2 weeks. Clinical examination showed multiple vesicubullous eruptions on dorsum of bilateral foot, dorsum of hands. There was a focus of intertriginous dermatitis involving right lateral toe cleft with maceration and fissuring. A scraping from the lesion demonstrated fungal hyphae with $10 \% \mathrm{KOH}$ preparation but not from the vesicular eruption. A diagnosis of Id reaction due to Tinea Pedis was made. Patient was started on topical and oral antifungal along with antihistamines and he responded well with the treatment.
\end{abstract}

Key words: Id reaction, T.Pedis (Tinea pedis)

\section{Case history}

A 15 year old boy presented with sudden onset of pompholyx like eruption on acral areas involving bilateral hands and feet for 2 weeks. There was absence of any similar episodes in the past. None of family members were affected with similar symptoms. Clinical examination showed multiple vesicobullous eruptions on dorsum of bilateral foot, dorsum of hands. There was a focus of intertriginous dermatitis involving right lateral toe cleft with maceration and fissuring. There was no lesion elsewhere in the skin, scalp and mucous membranes. A scraping from the lesion was taken and also from the vesicular eruption and $10 \% \mathrm{KOH}$ preparation was made. The lesion from right toe cleft demonstrated fungal hyphae but not from the vesicular eruption.

\section{Diagnosis}

Dermatophytide (Ide or Id) reaction due to Tinea pedis.

\section{Treatment and follow up}

Patient was started on topical and oral antifungal along with antihistamines. Patient was reviewed after 2 Address for correspondence: drdeeptarapathak@yahoo.com weeks and he responded well with the treatment with clearance of all lesions.

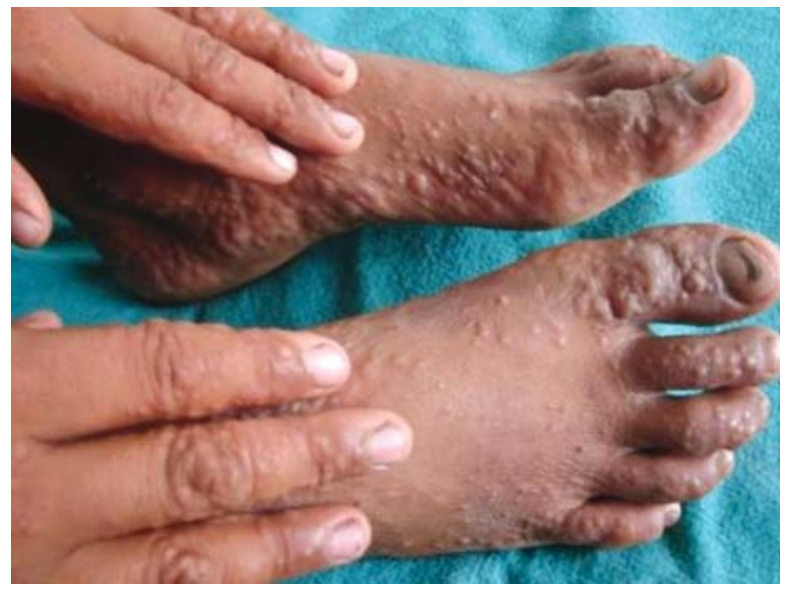

Fig. 1: Pompholyx like eruption on hands and feet 


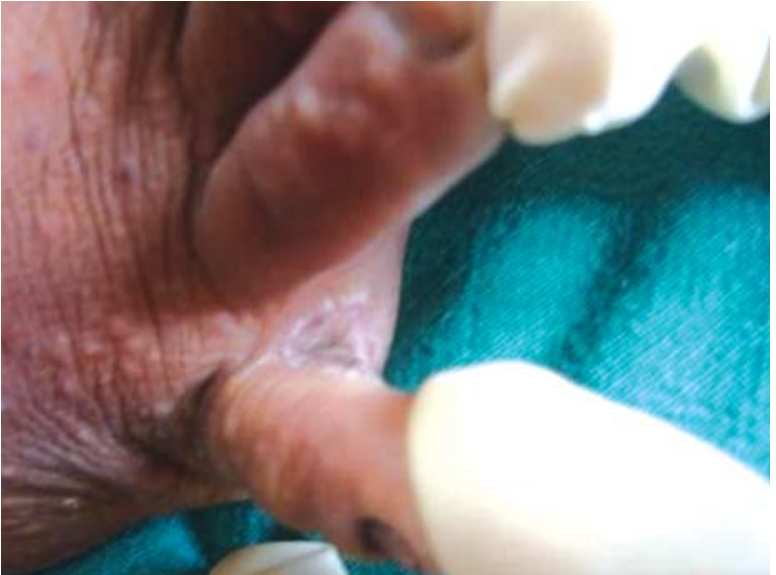

Fig. 2: T. pedis of right lateral toe cleft

\section{Discussion}

Id reaction is defined as distant, localized or generalized acute cutaneous reaction to an infectious and inflammatory skin condition ${ }^{1,2}$. The eruption has been referred to as dermatophytid, pediculid, or bacterid according to the corresponding infectious process ${ }^{3}$. The cause of the id reaction is unknown, but according to some authorities it is considered to be as immunologic in origin due to increased stimulation of normal $\mathrm{T}$ cells by altered skin constituents, dissemination of infectious antigen with a secondary response and hematogenous dissemination of cytokines from a primary site ${ }^{4,5}$. Absence of fungi in the dermatophytid lesions and clearing of the dermatophytid lesions after the fungus is eradicated are necessary to confirm a definitive diagnosis of a dermatophytide reaction. Id eruption tends to subside spontaneously when the primary focus is cured. In practice Id reaction is a clue that a person has tinea infection and it should alert the physician for abrupt treatment of acute tinea infection.

\section{References}

1. Hay RJ, Moore MK. Mycology. In: Rooks Textbook of Dermatology. $7^{\text {th }}$ ed.USA :Blackwell publishing; USA :2004.p. 31.34.

2. Ackerman $A B$, Chongchitnant $N$, Sanchez $J$, et al. Allergic contact dermatitis/nummular dermatitis/ dyshidrotic dermatitis/id reaction. In: Histologic DiagnosisofInflammatorySkinDiseases. Baltimore, Md: Williams \& Wilkins; 1997:184-6.

3. Brenner S, Ophir J, Krakowski A. Pediculid. An unusual -id reaction to pediculosis capitis. Dermatologica. 1984; 168(4):189-91.

4. Cunningham MJ, Zone JJ, Petersen MJ, Green JA. Circulating activated (DR-positive) T lymphocytes in a patient with autoeczematization. $J$ Am Acad Dermatol. Jun 1986; 14(6):1039-41.

5. Kasteler JS, Petersen MJ, Vance JE, Zone JJ. Circulating activated $T$ lymphocytes in autoeczematization. Arch Dermatol. Jun 1992; 128(6):795-8. 